\title{
NOTAS
}

\section{Gopchu: una aproximación al patrimonio arqueológico desconocido de Sihuas}

\section{Gopchu: an approach to the unknown archaeological heritage of Sihuas}

\author{
Giancarlos Castillo Flores \\ https://orcid.org/oooo-0002-8137-2601 \\ Universidad Nacional Mayor de San Marcos \\ giancarlos.castillo@unmsm.edu.pe
}

\section{INTRODUCCIÓN}

La región norte del callejón de Conchucos, no ha gozado de la atención debida en términos investigativos desde hace muchos años, en comparación con la parte sur del mismo u otras zonas de la región Áncash. El área comprendida por la provincia de Sihuas se ha caracterizado por la escasez de estudios arqueológicos, así como por los contados esfuerzos por demarcar, catastrar y proteger los sitios arqueológicos, como bien puede uno comprobar al conversar con los pobladores locales, quienes expresan su preocupación ante la falta de interés por su patrimonio arqueológico.

Uno de los pocos trabajos que han abordado a la zona, es el publicado por Astuhuamán y Espinoza (2006), donde presentan los datos obtenidos en dos campañas de prospección realizadas en los años 1999 y 2003, para así ofrecer una primera aproximación al estudio arqueológico de la provincia de Sihuas, principalmente en lo referente al periodo Intermedio Temprano y al periodo Horizonte Tardío. 


\section{LAS INVESTIGACIONES ARQUEOLÓGICAS EN SIHUAS Y EL SITIO DE GOPCHU}

Fue la poca cantidad de investigaciones, lo que en julio de este año nos impulsó a realizar tareas de reconocimiento en la cuenca media del río Sihuas, que comprende los distritos de Sihuas y Cashapampa; con el objetivo de recolectar más información sobre la ocupación prehispánica de esta cuenca y dar a conocer los asentamientos prehispánicos que hasta el día de hoy han permanecido en el anonimato para gran parte de la comunidad arqueológica en el Perú.

El sitio de Gopchu o Gopchjirca, corresponde a uno de los asentamientos prehispánicos más impresionantes que el equipo de investigación logro reconocer durante las labores de campo, no solo por sus características arquitectónicas, sino por la propia ubicación del mismo, dotando al sitio de componentes paisajísticos notables.

Ubicado en las coordenadas 208305.97 E y 9050100.41 N, a una elevación de 4070 m s. n. m., el sitio de Gopchu se encuentra emplazado sobre la cima del cerro homónimo en la margen derecha de la quebrada Colpa, la cual a su vez se ubica en la margen derecha del río Sihuas; políticamente se encuentra en las inmediaciones del anexo de Choquibamba, en el distrito sihuasino de Cashapampa.

El asentamiento tiene una extensión aproximada de 8 hectáreas, y se encuentra conformado por agrupaciones de múltiples recintos cuadrangulares y rectangulares que varían en tamaño, separados por espacios similares a calles que permiten movilizarse dentro del sitio y trasladarse entre las agrupaciones de recintos, denotando así una compleja organización interna del espacio.

Las diversas estructuras del sitio han sido construidas utilizando piedra canteada en forma irregular, dispuestas por lo general en doble hilera, y unidas con argamasa de barro para una mejor estabilidad estructural.

El estado de conservación actual del sitio es regular, pues, aunque se observa el derrumbamiento de algunas estructuras, la mayoría de estas se encuentra aún en pie. El principal problema que se encontró durante los trabajos de reconocimiento fue la abundante vegetación que ha crecido en el sitio, lo cual hizo difícil una apreciación más detallada de ciertos elementos.

Sobre la funcionalidad del sitio, es posible, en base a la cantidad, distribución de recintos y composición interna del sitio, que este haya cumplido una función predominantemente residencial, aunque por las dimensiones, ubicación y características defensivas del asentamiento, no se descarta que haya constituido uno de los más importantes dentro de la jerarquía de la zona.

La cima del cerro Gopchu, donde se encuentra emplazado el sitio, se caracteriza por su superficie moderadamente plana, y el difícil acceso a esta, pues la cima del 


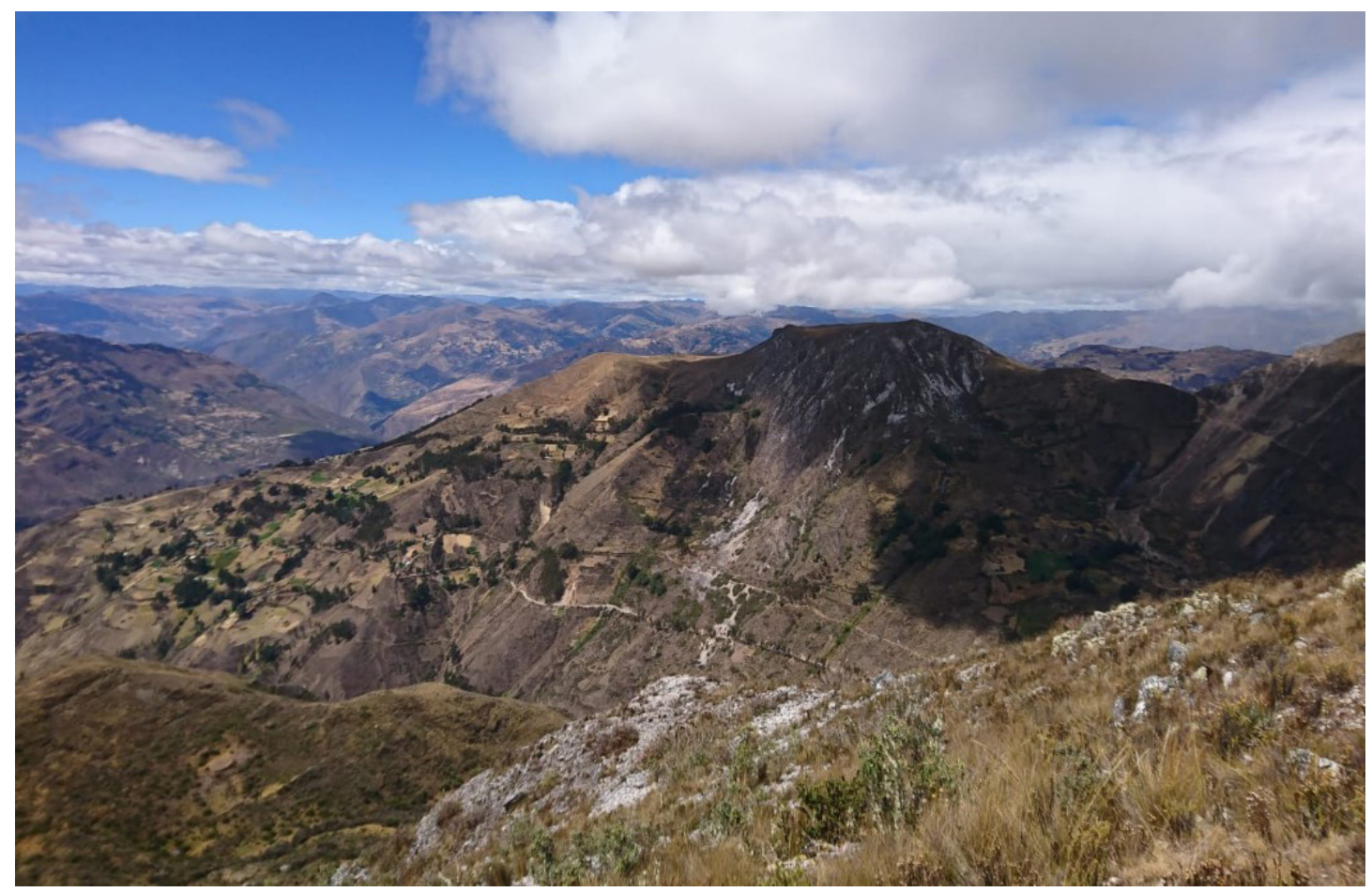

Figura 1. Vista general del cerro Gopchu (Foto de Castillo, G. 2021)

mismo está separada del resto del cerro por una pared rocosa casi vertical de aproximadamente 70 metros de altura.

La ladera suroeste del cerro, es la única que no cuenta con esta característica particular, siendo posiblemente por donde se realizara el acceso al sitio; debido a ellos es que en este sector encontramos el séxtuple muro del sitio, los cuales habrían cumplido posiblemente una función defensiva.

Las características geográficas de la cima del cerro Gopchu habrían hecho innecesaria la construcción de un muro perimétrico alrededor de todo el asentamiento debido a las características defensivas naturales que este lugar ofrece, por lo que solo habría sido necesario construir muros defensivos en la parte de más fácil acceso al sitio.

La filiación cultural del sitio, así como su temporalidad, queda aún para próximas discusiones, aunque las características y ubicación del mismo nos podría llevar a pensar que pertenece a periodos tardíos; sin embargo, todas estas interrogantes esperamos resolverlas en futuras investigaciones. 


\section{CONCLUSIONES}

Sin duda el sitio de Gopchu pudo haber constituido uno de los principales asentamientos de la cuenca media del río Sihuas, no solo por sus características arquitectónicas y defensivas, sino por su estratégica ubicación en el valle; ya que desde Gopchu es posible visualizar no solo la totalidad de la quebrada Colpa, sino gran parte del valle de Sihuas, así como el valle de Pasacancha y las múltiples quebradas de la margen opuesta, teniendo así una ubicación privilegiada para un control óptimo de gran parte del territorio.

Gopchu es testimonio del gran potencial arqueológico que la provincia de Sihuas puede ofrecer para el entendimiento de las sociedades prehispánicas de nuestro país; esperamos poder continuar con las labores de investigación en esta zona, para seguir completando la información que este y otros sitios nos puedan ofrecer, contribuyendo así con el conocimiento del pasado prehispánico de Sihuas y el fortalecimiento de la identidad cultural de sus pobladores.

\section{REFERENCIAS BIBLIOGRÁFICAS}

Astuhuamán, C. y Espinoza, D. (2006). Una aproximación a la arqueología de Sihuas. Periodo Intermedio Temprano y Horizonte tardío. En la complejidad Social en la sierra de Ancash. Lima: C. Orsini y K. Lane.

\section{SOBRE EL AUTOR}

\section{GIANCARLOS CASTILLO FLORES}

Giancarlos Castillo Flores, natural de Lima; estudiante de último año de la escuela académico profesional de arqueología en la Universidad Nacional Mayor de San Marcos; ha participado en múltiples proyectos de investigación arqueológica desde el 2017 hasta la actualidad en Lima y Áncash, así como en proyectos de evaluación arqueológica, conservación y restauración; actualmente desarrolla trabajos de investigación arqueológica en la provincia de Sihuas (Áncash). 